\title{
Dynamic Characteristics of an Elastic Structure with Thermal Effects
}

\section{Guanhua Xu}

The State Key Laboratory of Fluid Power and Mechatronic Systems, College of Mechanical Engineering, Zhejiang University, Hangzhou 310027, China.

Key Laboratory of 3D Printing Process and Equipment of Zhejiang Province, College of Mechanical Engineering, Zhejiang University, Hangzhou 310027, China.

Zhejiang University Kunshan Innovation Institute, Kunshan 215347, China.

Suzhou Zijingang Intelligent Manufacturing Equipment Co., Ltd., Kunshan 215347, China.

Zhejiang Bofine Power Equipment Co., Ltd., Jiaxing 314303, China

\section{Jianzhong $\mathrm{Fu}$, Wen He, Yuetong $\mathrm{Xu}$ and Zhiwei Lin}

The State Key Laboratory of Fluid Power and Mechatronic Systems, College of Mechanical Engineering, Zhejiang University, Hangzhou 310027, China.

Key Laboratory of 3D Printing Process and Equipment of Zhejiang Province, College of Mechanical Engineering, Zhejiang University, Hangzhou 310027, China.

\section{Bangping Gu}

College of Logistics Engineering, Shanghai Maritime University, Shanghai 201306, China.

\author{
Jiafu Zhang \\ School of Mechanical Engineering, Tianjin University, Tianjin 300350, China.
}

(Received 13 November 2018; accepted 10 December 2018)

The vibration table in a combination environmental testing device suffers from temperature changes, which cause the dynamic characteristics of the vibration structure to vary. The mechanism of the thermal effect on the dynamic characteristics of an elastic structure is presented, and a modal analysis with thermal effects based on the finiteelement method (FEM) is carried out. The results show that the natural frequencies for each order decrease as the temperature increases, while the mode shapes of the vibrator do not change with temperature. Although thermal stress may affect natural frequencies due to the additional initial stress element stiffness, this stress can be neglected in the modal analysis because it is negligible relative to the effect of the material property changes with temperature.

\section{NOMENCLATURE}

$\mathbf{X} \quad$ Vibration displacement vector, $\mathrm{m}$

$\mathbf{P}(t)$ Nodal load vector, $\mathrm{N}$

M Mass matrix, $\mathrm{kg}$

C Damping matrix, $\mathrm{N} /(\mathrm{m} / \mathrm{s})$

K Stiffness matrix, N/m

$\mathbf{M}^{e} \quad$ Element mass matrix, $\mathrm{kg}$

$\mathbf{K}^{e} \quad$ Element stiffness matrix, N/m

$\rho \quad$ Material density, $\mathrm{kg} / \mathrm{m}^{3}$

N Shape function

B Geometric matrix, 1/m

D Elastic coefficient matrix, GPa

E Material elastic modulus, GPa

$\mu \quad$ Poisson's ratio

$\varphi_{i} \quad$ Modal vector

$n \quad$ Number of nodal degrees of freedom

$\omega_{i} \quad$ Vibration frequency, $\mathrm{rad} / \mathrm{s}$

$\Gamma \quad$ Stress matrix, $\mathrm{Pa}$

G Shape function matrix

$\mathbf{C}_{H} \quad$ Heat capacity matrix, J/K

$\mathbf{K}_{H} \quad$ Heat transfer matrix, W/K
Q Node heat flow rate vector, W

T Structural node temperature vector, $\mathrm{K}$

$\dot{\mathbf{T}}$ Derivative vector of temperature versus time, $\mathrm{K} / \mathrm{s}$

$\mathbf{C}_{H}{ }^{e}$ Element heat capacity matrix, $\mathbf{J} / \mathrm{K}$

$\mathbf{K}_{H}{ }^{e}$ Element heat transfer matrix, W/K

$\mathbf{Q}^{e} \quad$ Element heat load vector, $\mathrm{W}$

$G_{v} \quad$ Heat generation per unit volume, $\mathrm{W} / \mathrm{m}^{3}$

$c_{p} \quad$ Specific heat, $\mathrm{J} /(\mathrm{kg} \cdot \mathrm{K})$

$q \quad$ Boundary heat flux, $\mathrm{W} / \mathrm{m}^{2}$

$\alpha \quad$ Heat transfer coefficient, $\mathrm{W} /\left(\mathrm{m}^{2} \cdot \mathrm{K}\right)$

$T_{a} \quad$ Ambient temperature, $\mathrm{K}$

$\partial \Omega \quad$ Boundary

$\varepsilon_{0} \quad$ Initial thermal strain vector

$\varepsilon \quad$ Total strain vector

$\beta \quad$ Thermal expansion coefficient, $1 / \mathrm{K}$

$\boldsymbol{\sigma}$ Thermal stress vector, $\mathrm{Pa}$

$\mathbf{P}_{f} \quad$ Body load vector, $\mathrm{N}$

$\mathbf{P}_{s} \quad$ Surface load vector, $\mathrm{N}$

$\mathbf{P}_{\varepsilon_{0}} \quad$ Structural node load vector caused by initial thermal strain, $\mathrm{N}$

$\mathbf{K}_{T} \quad$ Stiffness matrix that varies with the temperature, $\mathrm{N} / \mathrm{m}$

$\mathbf{K}_{\sigma} \quad$ Initial stress stiffness matrix, $\mathrm{N} / \mathrm{m}$ 
$T_{s} \quad$ Temperature of the structure, $\mathrm{K}$

$k_{s} \quad$ Thermal conductivity of the structure, $\mathrm{W} /(\mathrm{m} \cdot \mathrm{K})$

$T_{\text {in }}$ Temperature of the fluid inside the chamber, $\mathrm{K}$

$\alpha_{s}^{\text {in }} \quad$ Convective heat transfer coefficient on the surface of the structure inside the chamber, $\mathrm{W} /\left(\mathrm{m}^{2} \cdot \mathrm{K}\right)$

$T_{\text {out }}$ Ambient temperature outside the chamber, $\mathrm{K}$

$\alpha_{s}^{\text {out }}$ Convective heat transfer coefficient on the surface of the structure outside the chamber, $\mathrm{W} /\left(\mathrm{m}^{2} \cdot \mathrm{K}\right)$

\section{INTRODUCTION}

Sensors and electronic devices on spacecraft experience complex combinations of environmental factors, including vibration and temperature. To test the reliability of these devices, combination environmental testing devices are essential. Generally, a device for combination environmental testing that involves vibration and temperature changes is composed of a vibrator and a temperature test chamber. A combination environmental testing device was designed with a vibration table mounted in a temperature test chamber. Therefore, the moving parts of the vibrator will be affected by the temperature field in the chamber, especially the dynamic characteristics of the elastic structure of the vibrator.

Thermal effects on the dynamic characteristics of elastic structures have been studied widely in the past. For instance, the vibration characteristics of multilayered sandwich plates, e.g., functionally graded material (FGM) plates, have been investigated by many scholars. Yang et al. confirmed that the vibration characteristics and dynamic responses are significantly influenced by the material composition, temperature increase, in-plane and out-of-plane boundary conditions, initial membrane stress, and dynamic load shape. ${ }^{1}$ Jeyaraj et al. studied the vibration and acoustic response characteristics of a fiberreinforced composite plate in a thermal environment by considering the inherent material damping property of the composite material. ${ }^{2}$ Similar studies were carried out by Kumar et al. ${ }^{3}$ The free vibrations of FGM rectangular plates with simply supported and clamped edges in a thermal environment were studied by Li et al. ${ }^{4}$ Duc et al. investigated the nonlinear response of functionally graded cylindrical panels to temperature effects under a uniform lateral pressure by an analytical approach. ${ }^{5}$ Malekzadeh et al. studied the free vibration of FGM plates, including arbitrary straight-sided quadrilateral plates ${ }^{6}$ and annular plates, ${ }^{7}$ in a thermal environment by the differential quadrature method. The vibration and acoustic responses of sandwich panels ${ }^{8}$ and asymmetric laminated plate ${ }^{9}$ in a thermal environment were studied using both the first-order shear deformation plate theory and the Rayleigh integral by Li's team. A similar study was reported by $\mathrm{Li}$, et al. ${ }^{10}$ Pandey et al. presented a layer-based finite element formulation for dynamic analysis of FGM sandwich plates in a thermal environment. ${ }^{11}$ Padhi et al. utilized a high-order zig-zag laminate theory to investigate the behavior of sandwich laminated materials subjected to thermal loading. ${ }^{12}$ Moreover, as hypersonic vehicles are exposed to combined aerodynamic, thermal, and acoustic conditions during flight, many studies have attempted to determine the dynamic characteristics of aerospace vehicle panel structures. Huang et al. analyzed the modal structure of a variable thickness plate under a transient thermal environment. ${ }^{13}$ Similar research was carried out with FEM to investigate the thermal effects on aerospace vehicle panel structures. ${ }^{14-16}$ Tan et al. developed a thermal-modal test system, tested normal modes under several thermal circumstances and verified the experimental results by the FEM method. ${ }^{17} \mathrm{Li}$ et al. carried out a thermal-modal analysis of a thermally resistant panel structure to provide guidance for thermal load design. ${ }^{18}$ In addition, thermal vibrational analyses of other structures, e.g., simply supported and clamped beams, ${ }^{19}$ clamped rectangular plates,${ }^{20}$ exhaust manifolds, ${ }^{21}$ rotating blades, ${ }^{22}$ turbine stators, ${ }^{23}$ spur gears,${ }^{24}$ and damped Timoshenko beams, ${ }^{25}$ have been conducted.

In this study, the dynamic characteristics of an elastic structure with thermal effects are studied using a combination environmental testing device. First, the mechanism of the thermal effect on the dynamic characteristics of the elastic structure is presented, and the modal analysis process with thermal effects based on FEM is given. Then, a modal analysis of a vibrator under a thermal environment is carried out based on ANSYS Workbench 16.0. Finally, some results are summarized.

\section{DYNAMIC CHARACTERISTICS OF AN ELASTIC STRUCTURE WITH THERMAL EFFECTS}

The dynamic characteristics of an elastic structure are affected by the material properties and internal stress of the structure. A change in temperature not only causes variations in material properties but also causes thermal stress inside a structure due to uneven temperature changes and boundary constraint conditions, and these changes result in changes in the dynamic characteristics of the structure. To study the dynamic characteristics of an elastic structure with the influence of a thermal environment, a free vibration modal analysis of a vibrator in a temperature field is carried out.

\subsection{Modal Analysis of an Elastic Structure}

Modal analysis is a classical eigenvalue problem. According to modal analysis theory, an elastic structure is usually regarded as a mass, spring and damping system and is separated into a finite number of connected rigid bodies. By regarding such a system as a linear time-invariant system, the equation of motion can be written as ${ }^{26}$

$$
\mathbf{M} \ddot{\mathbf{x}}+\mathbf{C} \dot{\mathbf{x}}+\mathbf{K x}=\mathbf{P}(t) .
$$

When $\mathbf{P}(t)=0$, Eq. (1) is the free-vibration equation of an elastic structure. The damping ratios of most structures are very small, and the effects of structural damping on the free-vibration frequency and mode can be neglected. Consequently, the free-vibration equation for an elastic structure without damping can be expressed as

$$
\mathrm{M} \ddot{\mathbf{x}}+\mathrm{Kx}=0 .
$$

In this equation, the mass matrix and stiffness matrix are composed of the element mass matrix and the element stiffness matrix, respectively, of the elastic structure, which can be expressed as

$$
\mathbf{M}=\sum_{e} \mathbf{M}^{e} ; \quad \mathbf{K}=\sum_{e} \mathbf{K}^{e} .
$$

The element mass matrix and element stiffness matrix can be expressed as ${ }^{26}$

$$
\mathbf{M}^{e}=\int_{\Omega} \rho \mathbf{N}^{\mathrm{T}} \mathbf{N} \mathrm{d} \Omega ;
$$




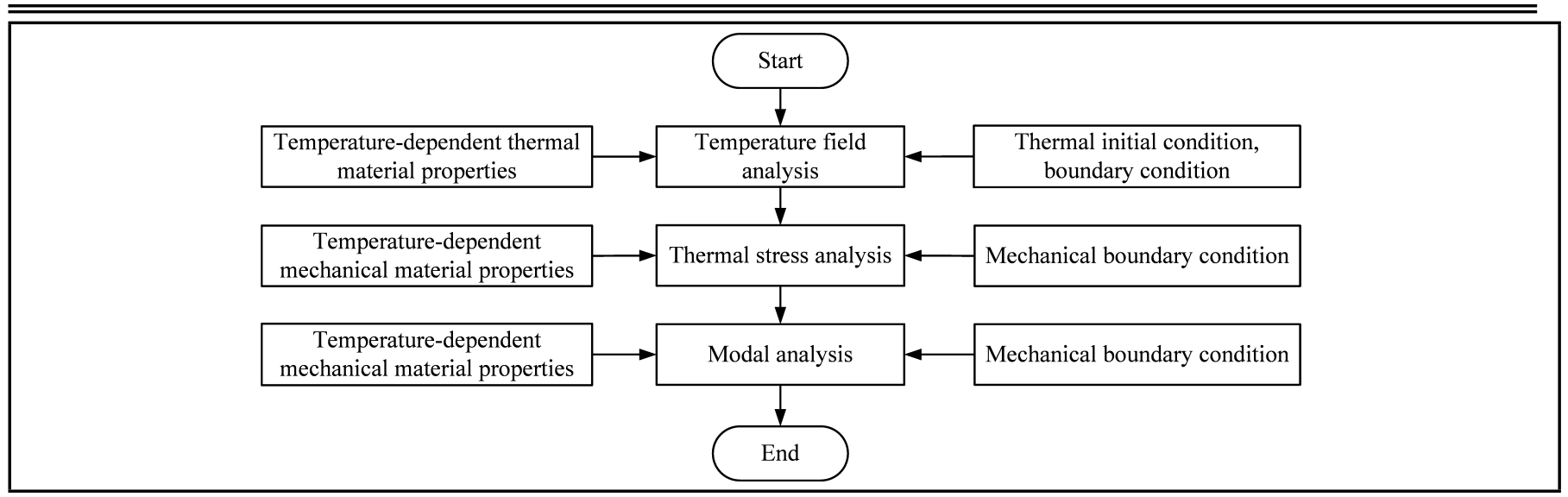

Figure 1. Modal analysis process with thermal effects.

$$
\mathbf{K}^{e}=\int_{\Omega} \mathbf{B}^{\mathrm{T}} \mathrm{DBd} \Omega
$$

If the free vibration of a structure is harmonic, the vibration displacement can be expressed as

$$
\mathbf{x}=\varphi \cdot \cos \omega t
$$

Substituting the above equation into Eq. (2), a homogeneous equation can be obtained as

$$
\left(\mathbf{K}-\omega^{2} \mathbf{M}\right) \boldsymbol{\varphi}=0 .
$$

Since the vibration amplitude of each node in a structure is not always zero, the free-vibration frequency satisfies the following equation,

$$
\left|\mathbf{K}-\omega^{2} \mathbf{M}\right|=0 .
$$

Since the stiffness matrix and the mass matrix are $n$-order square matrices, the above equation is an $n$-th algebraic equation with respect to $\omega^{2}$, and the free-vibration frequency of a structure can be obtained as

$$
\omega_{1} \leq \omega_{2} \leq \cdots \leq \omega_{n}
$$

These frequencies are the eigenvalues of Eq. (7). For each vibration frequency, $\omega_{i}$, a set of eigenvectors, $\varphi_{i}=$ $\left[\varphi_{i 1}, \quad \varphi_{i 2}, \quad \cdots, \quad \varphi_{\text {in }}\right]^{\mathrm{T}}$, can be determined by Eq. (7), and these eigenvectors are also called the modal vector at each frequency.

\subsection{Thermal Effects on the Modal Analysis}

From Eq. (8), it can be seen that the natural frequency of an elastic structure only depends on the mass matrix and stiffness matrix. In general, the mass matrix can be considered a constant matrix regardless of temperature changes. Therefore, the influence of a temperature field on the vibration mode of a structure is only caused by change in the stiffness matrix, and this change mainly includes two aspects. ${ }^{13,24}$ On the one hand, a change in temperature causes the elastic modulus and the Poisson's ratio of a material to change, leading to a change in the initial element stiffness matrix of a structure, which can be expressed as

$$
\mathbf{K}_{T}^{e}=\int_{\Omega} \mathbf{B}^{\mathrm{T}} \mathbf{D}_{T} \mathbf{B} \mathrm{d} \Omega
$$

On the other hand, as the temperature changes, thermal stress arises due to uneven temperature changes or boundary constraints in a structure, and the thermal stress will also generate an additional initial stress element stiffness matrix

$$
\mathbf{K}_{\sigma}^{e}=\int_{\Omega} \mathbf{G}^{\mathrm{T}} \mathbf{\Gamma} \mathbf{G d} \Omega .
$$

Therefore, the element stiffness matrix considering the thermal effect can be written as

$$
\mathbf{K}^{e}=\mathbf{K}_{T}^{e}+\mathbf{K}_{\sigma}^{e}
$$

\section{MODAL ANALYSIS PROCESS BASED ON FEM WITH THERMAL EFFECTS}

The modal analysis process with thermal effects is shown in Fig. 1. First, the temperature field of the structure is solved using the boundary conditions and the initial conditions of the temperature field and considering the material properties, e.g., thermal conductivity and specific heat capacity. Second, the temperature field obtained from the previous step is applied as the thermal load, and the thermal stress of the structure is obtained considering the material properties, e.g., thermal expansion coefficient, elastic modulus and Poisson's ratio. Then, the initial stress stiffness matrix of the structure is obtained by using the thermal stress results obtained from the previous step, and the final stiffness matrix is obtained considering the material properties that vary with temperature, e.g., density, elastic modulus and Poisson's ratio. Finally, the modal analysis with thermal effects can be carried out by solving Eq. (8).

\subsection{Temperature Field Analysis}

For the modal analysis with thermal effects, the temperature field of the structure must be obtained first. In fact, the terms related to the elastic strain rate in the heat conduction equation are coupled with the temperature, which means that the elastic strain rate of a structure will also affect the temperature distribution. However, the exact solution of the thermoelastic coupling equation is very complicated. Generally, as the elastic strain rate is very small, the effects of the coupling terms on the heat conduction equation can be neglected. Therefore, only the heat conduction equation is used to calculate the temperature field.

When the FEM is used for a heat conduction problem, the three-dimensional heat transfer equation of a structure can be 
transformed into a first-order system of equations, which can be written as ${ }^{13}$

$$
\mathbf{C}_{H} \dot{\mathbf{T}}+\mathbf{K}_{H} \mathbf{T}=\mathbf{Q}
$$

where the heat capacity matrix, heat transfer matrix and node heat flow rate vector are composed of the element matrices and element load vector, which can be expressed as

$$
\mathbf{C}_{H}=\sum_{e} \mathbf{C}_{H}{ }^{e} ; \quad \mathbf{K}_{H}=\sum_{e} \mathbf{K}_{H}^{e} ; \quad \mathbf{Q}=\sum_{e} \mathbf{Q}^{e} .
$$

The element matrices and element load vector can be expressed as $^{27}$

$$
\begin{gathered}
\mathbf{C}_{H}{ }^{e}=\int_{\Omega} \rho c_{p} \mathbf{N}^{\mathrm{T}} \mathbf{N} \mathrm{d} \Omega \\
\mathbf{K}_{H}{ }^{e}=\int_{\Omega} \mathbf{B}^{\mathrm{T}} \mathrm{DBd} \Omega+\int_{\partial \Omega_{\alpha}} \alpha \mathbf{N}^{\mathrm{T}} \mathbf{N} d s \\
\mathbf{Q}^{e}=\int_{\Omega} G_{v} \mathbf{N}^{\mathrm{T}} \mathrm{d} \Omega-\int_{\partial \Omega_{q}} q \mathbf{N}^{\mathrm{T}} d s+\int_{\partial \Omega_{\alpha}} \alpha T_{a} \mathbf{N}^{\mathrm{T}} d s
\end{gathered}
$$

The temperature field of a structure can be obtained by solving the ordinary differential equation of Eq. (13).

\subsection{Thermal Stress Analysis}

If structural deformation is small and elastic, when the temperature field load is known, the initial thermal strain of a node can be expressed as ${ }^{26}$

$$
\varepsilon_{0}=\beta\left(T-T_{0}\right)\left[\begin{array}{llllll}
1 & 1 & 1 & 0 & 0 & 0
\end{array}\right]^{\mathrm{T}} .
$$

Due to the physical constraints and uneven changes of a temperature field, an elastic structure cannot deform freely, which induces thermal stress in the structure. The total strain of an elastic structure equals the sum of the initial thermal strain and elastic strain, which can be expressed as ${ }^{13}$

$$
\varepsilon=\mathbf{D}^{-1} \boldsymbol{\sigma}+\varepsilon_{0} .
$$

Therefore, the thermal stress can be obtained as

$$
\boldsymbol{\sigma}=\mathbf{D}\left(\varepsilon-\varepsilon_{0}\right) .
$$

By substituting Eq. (20) into the principle of virtual displacement, the finite element expression of the thermal stress problem can be obtained as ${ }^{26}$

$$
\mathrm{Kx}=\mathbf{P}=\mathbf{P}_{f}+\mathbf{P}_{s}+\mathbf{P}_{\varepsilon_{0}}
$$

where the structural node load vector caused by the initial thermal strain can be expressed as

$$
\mathbf{P}_{\varepsilon_{0}}=\sum_{e} \int_{\Omega} \mathbf{B}^{\mathrm{T}} \mathbf{D}_{T} \boldsymbol{\varepsilon}_{0} \mathrm{~d} \Omega
$$

In fact, compared with a general structural stress analysis without a heat load, structural thermal stress only augments the load vector $\mathbf{P}_{\varepsilon_{0}}$ due to the initial thermal strain.

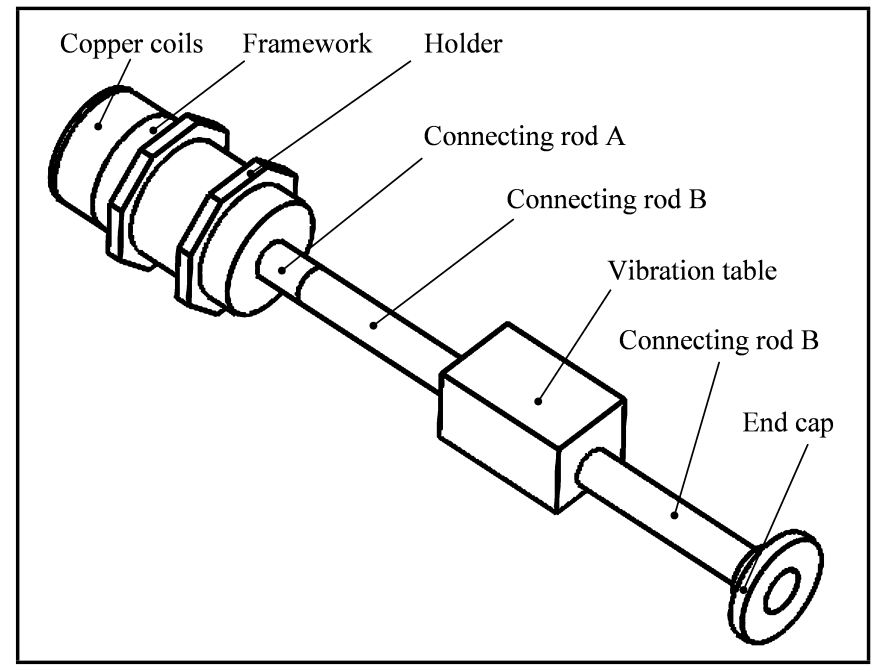

Figure 2. Structure of the vibrator.

\subsection{Modal Analysis}

After the temperature field and stress field of the structure are obtained, the stiffness matrix, $\mathbf{K}_{T}$, that varies with temperature can be obtained based on the material properties. The initial stress stiffness matrix, $\mathbf{K}_{\sigma}$, of a structure can also be obtained according to the stress field. Thus, the final stiffness matrix, $\mathbf{K}$, can be obtained by integrating the above two stiffness matrices. In this case, by incorporating the mass matrix, $\mathbf{M}$, the modal of a structure with thermal effects can be obtained by solving Eq. (8).

\section{MODAL ANALYSIS OF A VIBRATOR WITH THERMAL EFFECTS}

To study the effects of a temperature field on the dynamic characteristics of an elastic structure and considering both the thermal stress and the change in material properties with temperature, a modal analysis of a vibrator with thermal effects is carried out by using the commercial finite element analysis software Ansys Workbench 16.0.

\subsection{Modeling and Material Settings}

\subsubsection{Structure of the vibrator}

The vibrator is the moving part of an electromagnetic vibration table used in combination environment tests. The vibrator experiences a thermal environment during environmental testing. The vibrator structure is shown in Fig. 2. The vibrator is mainly composed of a vibration table, a moving coil, connecting rod A, connecting rod B and an end cap. The moving coil is composed of a holder, framework and copper coils. The vibration table and connecting rod B are mounted inside the environmental test chamber, while the other parts are mounted outside the environmental test chamber.

\subsubsection{Material properties}

The vibration table, holder and end cap are made of aluminum alloy; connecting rod $\mathrm{A}$ and connecting rod $\mathrm{B}$ are made of $45 \mathrm{steel}$; and the framework of the moving coil is made of fiber-reinforced plastic (FRP). The material properties of each material are shown in Tab. 1 - Tab. 4. Since the moving coil is mounted outside the environmental test chamber and the temperature change of the coil is small, the material properties of 


Table 1. Material properties of 45 steel.
\begin{tabular}{|l|l|l|l|l|l||}
\hline Temperature $/{ }^{\circ} \mathrm{C}$ & 22 & 100 & 200 & 300 & 400 \\
\hline Density / $\left(\mathrm{kg} / \mathrm{m}^{3}\right)$ & 7810 & 7810 & 7810 & 7810 & 7810 \\
Elastic modulus / GPa & 200 & 201 & 193 & 190 & 172 \\
Poisson's ratio & 0.28 & 0.28 & 0.28 & 0.28 & 0.28 \\
Thermal conductivity / & 48.15 & 48.15 & 46.47 & 41.45 & 38.10 \\
{$[\mathrm{~W} /(\mathrm{m} \cdot \mathrm{K})]$} & & & & & \\
Thermal expansion / K ${ }^{-1}$ & $1.16 \mathrm{e}-5$ & $1.19 \mathrm{e}-5$ & $1.23 \mathrm{e}-5$ & $1.31 \mathrm{e}-5$ & $1.37 \mathrm{e}-5$ \\
Specific heat / $[\mathrm{J} /(\mathrm{kg} \cdot \mathrm{K})]$ & 469 & 469 & 482 & 523 & 550 \\
\hline
\end{tabular}

Table 5. Relative error analysis with different grid sizes.

\begin{tabular}{|l|l|l|l|l|}
\hline $\begin{array}{l}\text { Element } \\
\text { size }(\mathrm{m})\end{array}$ & $\begin{array}{l}\text { Maximum tem- } \\
\text { perature }\left({ }^{\circ} \mathrm{C}\right)\end{array}$ & $\begin{array}{l}\text { Deviation } \\
(\%)\end{array}$ & $\begin{array}{l}\text { First-order natural } \\
\text { frequency }(\mathrm{Hz})\end{array}$ & $\begin{array}{l}\text { Deviation } \\
(\%)\end{array}$ \\
\hline 0.01 & 92.215 & - & 405.45 & - \\
0.008 & 92.268 & -0.057 & 404.76 & 0.170 \\
0.006 & 92.281 & -0.014 & 402.37 & 0.590 \\
0.004 & 92.265 & 0.017 & 401.14 & 0.306 \\
0.002 & 92.283 & -0.020 & 401.21 & -0.017 \\
\hline
\end{tabular}

Table 2. Physical properties of LY12 hard aluminum alloy.

\begin{tabular}{|l|l|l|l|l|l||}
\hline Temperature $/{ }^{\circ} \mathrm{C}$ & 22 & 100 & 200 & 300 & 400 \\
\hline Density $/\left(\mathrm{kg} / \mathrm{m}^{3}\right)$ & 2800 & 2800 & 2800 & 2800 & 2800 \\
Elastic modulus / GPa & 70 & 66 & 59 & 50 & - \\
Poisson's ratio & 0.33 & 0.33 & 0.33 & 0.33 & 0.33 \\
Thermal conductivity $/$ & 117 & 130 & 151 & 172 & 176 \\
{$[\mathrm{~W} /(\mathrm{m} \cdot \mathrm{K})]$} & & & & & \\
Thermal expansion / K ${ }^{-1}$ & $2.14 \mathrm{e}-5$ & $2.27 \mathrm{e}-5$ & $2.38 \mathrm{e}-5$ & $2.47 \mathrm{e}-5$ & - \\
Specific heat $/[\mathrm{J} /(\mathrm{kg} \cdot \mathrm{K})]$ & 921 & 921 & 1047 & 1130 & - \\
\hline
\end{tabular}

Table 3. Material properties of copper.

\begin{tabular}{|l|l|l|l|l|l|}
\hline $\begin{array}{l}\text { Density / } \\
\left(\mathrm{kg} / \mathrm{m}^{3}\right)\end{array}$ & $\begin{array}{l}\text { Elastic } \\
\text { modulus } \\
\mathrm{GPa}\end{array}$ & $\begin{array}{l}\text { Poisson's } \\
\text { ratio }\end{array}$ & $\begin{array}{l}\text { Thermal } \\
\text { conductivity } \\
/[\mathrm{W} /(\mathrm{m} \cdot \mathrm{K})]\end{array}$ & $\begin{array}{l}\text { Thermal } \\
\text { expansion } \\
\mathrm{K}^{-1}\end{array}$ & $\begin{array}{l}\text { Specific } \\
\text { heat } \\
{[\mathrm{J} /(\mathrm{kg} \cdot \mathrm{K})]}\end{array}$ \\
\hline 8670 & 106 & 0.32 & 140 & $1.9 \mathrm{e}-5$ & 389 \\
\hline
\end{tabular}

Table 4. Material properties of FRP.

\begin{tabular}{|l|l|l|l|l|l|}
\hline $\begin{array}{l}\text { Density / } \\
\left(\mathrm{kg} / \mathrm{m}^{3}\right)\end{array}$ & $\begin{array}{l}\text { Elastic } \\
\text { modulus } \\
\mathrm{GPa}\end{array}$ & $\begin{array}{l}\text { Poisson's } \\
\text { ratio }\end{array}$ & $\begin{array}{l}\text { Thermal } \\
\text { conductivity } \\
/[\mathrm{W} /(\mathrm{m} \cdot \mathrm{K})]\end{array}$ & $\begin{array}{l}\text { Thermal } \\
\text { expansion } \\
\mathrm{K}^{-1}\end{array}$ & $\begin{array}{l}\text { Specific } \\
\text { heat } \\
{[\mathrm{J} /(\mathrm{kg} \cdot \mathrm{K})]}\end{array}$ \\
\hline 1800 & 20 & 0.3 & 0.4 & $7 \mathrm{e}-6$ & 1260 \\
\hline
\end{tabular}

the moving coil, i.e., copper and FRP, are considered constant regardless of the temperature change.

\subsection{Boundary Conditions}

The vibration table and connecting rod B are placed in the environmental test chamber, and heat diffuses from an internal fluid through convection and heat conduction to the vibration table and other parts. Thus, the Robin boundary condition on the surface of the vibration table and connecting rod $\mathrm{B}\left(\partial \Omega_{1}\right)$ is

$$
k_{s}\left(\frac{\partial T_{s}}{\partial n}\right) \mid \partial \Omega_{1}=\alpha_{s}^{\text {in }}\left(\left.T_{s}\right|_{\partial \Omega_{1}}-T_{\text {in }}\right) .
$$

Considering that the other parts of the vibrator are outside the environmental test chamber, heat dissipates into the air from the surface of the vibrator by convection and heat conduction. Therefore, the Robin boundary condition on the surface $\left(\partial \Omega_{2}\right)$ of the remaining parts is

$$
\left.k_{s}\left(\frac{\partial T_{s}}{\partial n}\right)\right|_{\partial \Omega_{2}}=\alpha_{s}^{\text {out }}\left(\left.T_{s}\right|_{\partial \Omega_{2}}-T_{\text {out }}\right) .
$$

To solve the free-vibration model of the vibrator, all the structural surface loads are assumed to be 0 when solving for the thermal stress.

\subsection{Grid Study}

A grid mesh of the vibrator was automatically created by Ansys Workbench using mixed grids of hexahedrons and tetrahedrons. A detailed grid independence study was performed, and five different mesh sizes were adopted to check the mesh independence. The maximum temperature and first-order natural frequency of the vibrator were obtained by a temperature

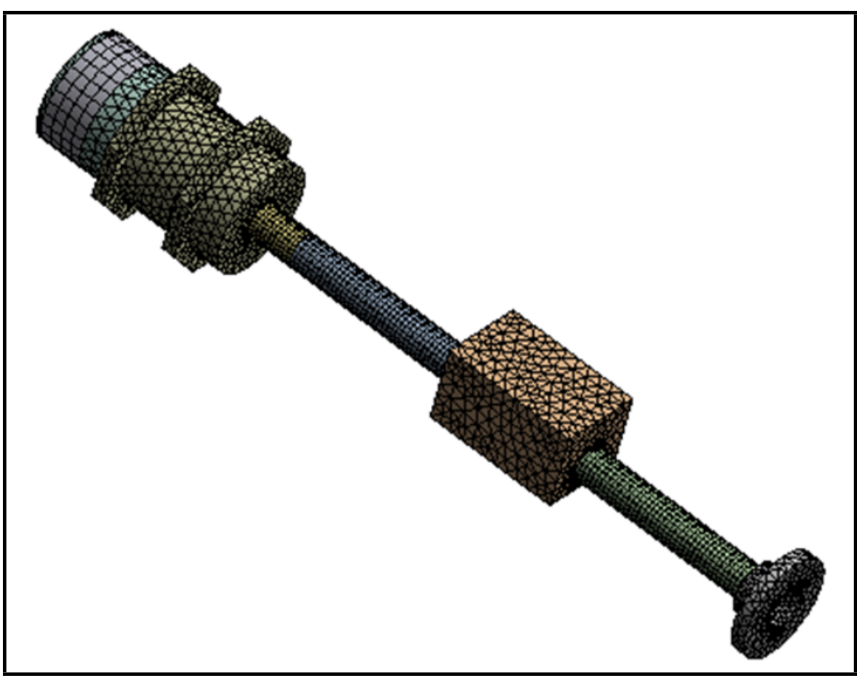

Figure 3. Grid mesh of the vibrator.

field analysis and a modal analysis, respectively. The results in Tab. 5 indicate that converged results were achieved. For two cases with different element sizes of $0.004 \mathrm{~m}$ and $0.002 \mathrm{~m}$, the differences in the maximum temperature and first-order natural frequency are below $0.1 \%$. Therefore, the solution is grid independent. Considering the calculation time, an element size of $0.004 \mathrm{~m}$ is adopted for the following solutions. The total number of nodes is 56993, and the number of units is 22614, as shown in Fig. 3.

\subsection{Results and Analysis}

\subsubsection{Temperature field results}

According to the temperature boundary conditions given by Eqs. (23) and (24), the temperature distribution of the vibrator is obtained and shown in Fig. 4. Figures 4(a) and 4(b) show the temperature field of the vibrator when the fluid temperature inside the test chamber is $100^{\circ} \mathrm{C}$ and $200^{\circ} \mathrm{C}$, respectively. The results show that the temperature distribution of the vibrator is similar regardless of the exact fluid temperature inside the test chamber. The temperature around the vibration table is relatively high, and the maximum temperature of the vibrator is 92.27 ${ }^{\circ} \mathrm{C}$ and $182.44{ }^{\circ} \mathrm{C}$ for the two cases above, respectively. The temperature of the coil moving away from the vibration table is relatively low, and the minimum temperature for the two cases is $36.59{ }^{\circ} \mathrm{C}$ and $55.24{ }^{\circ} \mathrm{C}$, respectively.

\subsubsection{Deformation and stress field results}

Using the solution from the temperature field analysis, the deformation of the vibrator is solved and shown in Fig. 5. Figures 5(a) and 5(b) show the deformation of the vibrator when the fluid temperature inside the test chamber is $100{ }^{\circ} \mathrm{C}$ and 200 ${ }^{\circ} \mathrm{C}$, respectively. The results show that the deformation pattern of the vibrator is similar, regardless of the exact fluid temperature inside the test chamber. The maximum deformation of the 


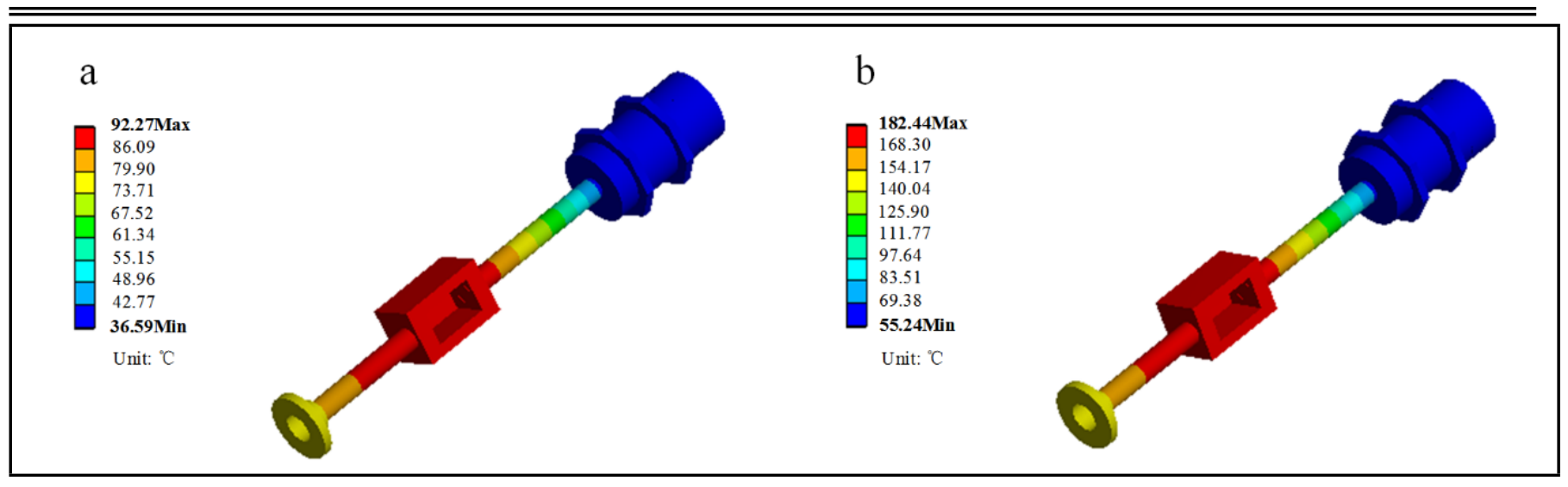

Figure 4. Temperature distribution of the vibrator, (a) $T_{\text {in }}=100^{\circ} \mathrm{C}$, (b) $T_{\text {in }}=200^{\circ} \mathrm{C}$.

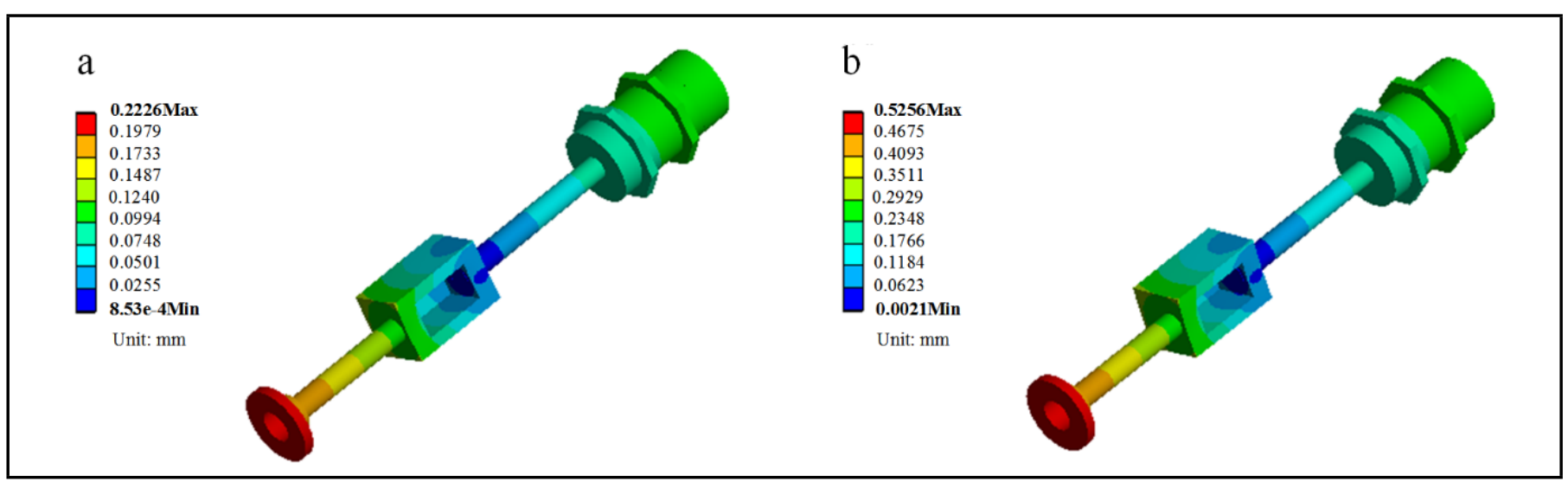

Figure 5. Deformation of the vibrator, (a) $T_{\text {in }}=100^{\circ} \mathrm{C}$, (b) $T_{\text {in }}=200^{\circ} \mathrm{C}$.

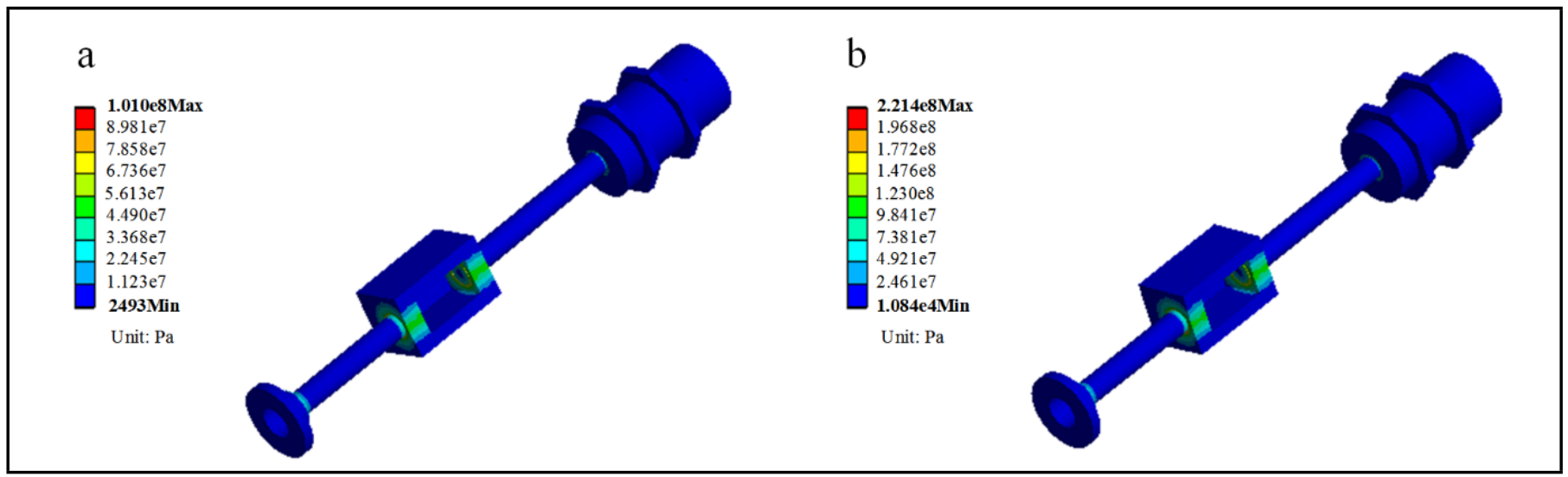

Figure 6. Thermal stress distribution of the vibrator, (a) $T_{\text {in }}=100{ }^{\circ} \mathrm{C}$, (b) $T_{\text {in }}=200{ }^{\circ} \mathrm{C}$.

vibrator is $0.2226 \mathrm{~mm}$ and $0.5256 \mathrm{~mm}$ for the two cases above, respectively, and the maximum deformation occurs at the end cap.

At the same time, the thermal stress of the vibrator is solved and shown in Fig. 6. Figures 6(a) and 6(b) show the thermal stress of the vibrator when the fluid temperature inside the test chamber is $100{ }^{\circ} \mathrm{C}$ and $200{ }^{\circ} \mathrm{C}$, respectively. The maximum thermal stress of the vibrator is 101.0 MPa and 221.4 MPa, respectively, for the two cases above. The results show that the stress distribution of the vibrator is similar, regardless of the exact fluid temperature inside the test chamber. The stress concentration occurs at the connection regions of different parts, especially the connection region between the vibration table and connecting rod $\mathrm{B}$. The reason for this concentration is that the temperatures of the different materials in the connection region are very close, but the linear expansion coefficients of different materials vary, causing unequal thermal expansion of the different parts. Therefore, the deformation of the different parts is constrained and thermal stress occurs. In addition, Tab. 1 and Tab. 2 show that the difference between the linear expansion coefficients of aluminum alloy and steel increases with temperature. Additionally, the deformation is proportional to the temperature. Therefore, the difference in the free deformations of these two materials increases with temperature, leading to an increase in the thermal stress at the connection region for the two parts made of different materials. This result demonstrates why a higher stress concentration occurs at the connection region between the vibration table and connecting rod $\mathrm{B}$. 


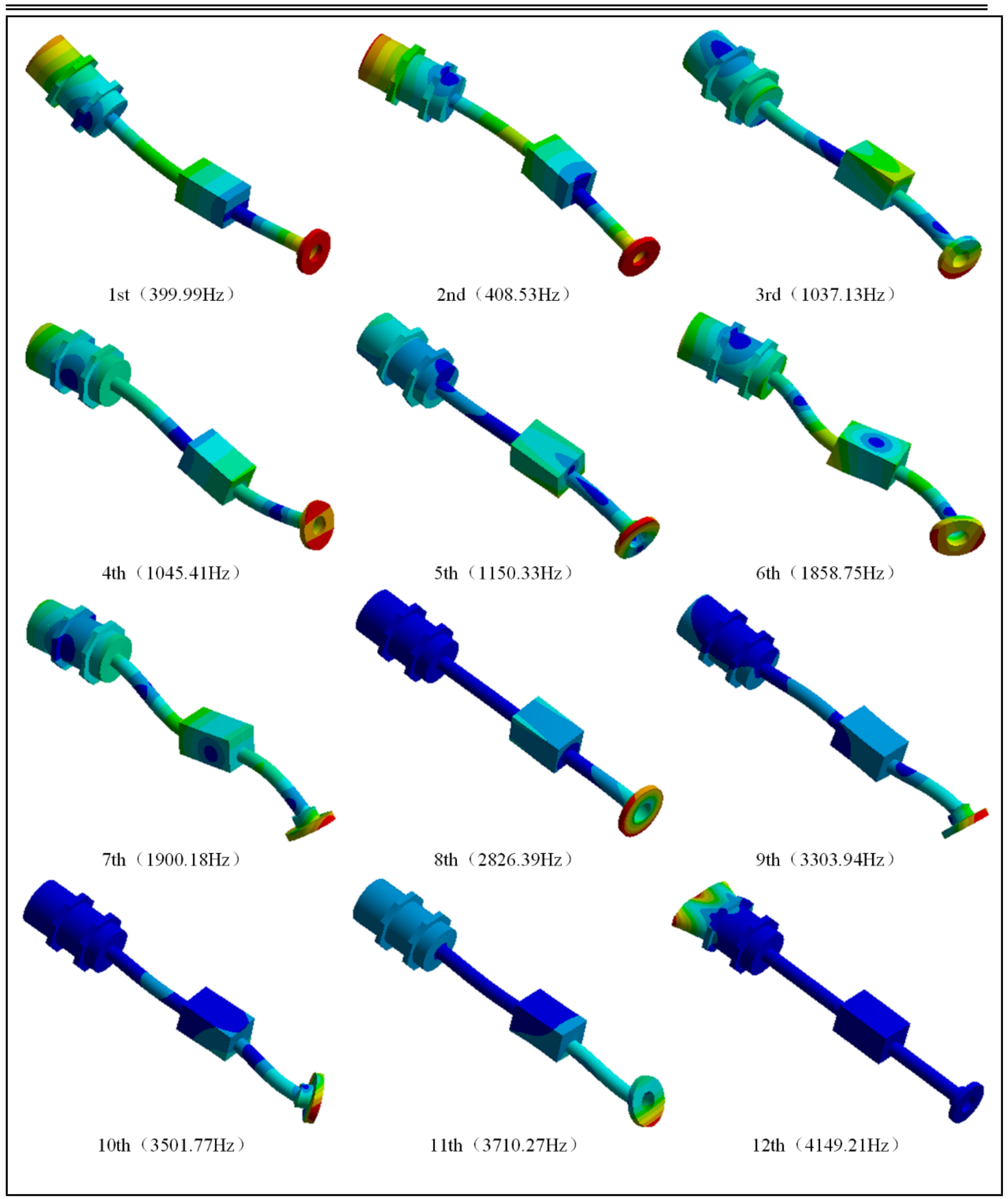

Figure 7. Mode shapes of the vibrator $\left(T_{\text {in }}=100^{\circ} \mathrm{C}\right)$.

\subsubsection{Modal analysis results}

Modal analysis is carried out using the obtained temperature field and stress field. Fig. 7 shows the first 12 mode shapes of the vibrator when the fluid temperature inside the test chamber is $100{ }^{\circ} \mathrm{C}$. The natural frequencies are all greater than the operating frequency range of the vibrator (below $300 \mathrm{~Hz}$ ). The results show that the 5 th and 8 th mode shapes indicate torsional vibration modes, the 12 th mode shape indicates a radial compress and extension vibration mode, and the remaining mode shapes all indicate bending vibration modes. As the direction of the bending vibration and the movement of the vibration table (along the axial direction of the connecting rod) are perpendicular to each other, these vibration modes have lit- 


\begin{tabular}{l}
\hline \hline Table 6. The first 12 orders of the natural frequency of the vibrator $(\mathrm{Hz})$. \\
\begin{tabular}{|l|l|l|l|l|l|l|l||}
\hline $\begin{array}{l}\text { Mode } \\
\text { No. }\end{array}$ & 22 & 50 & 100 & 150 & 200 & 250 & 300 \\
\hline 1 & 401.14 & 400.86 & 399.99 & 398.01 & 395.32 & 392.24 & 389.21 \\
2 & 409.36 & 409.16 & 408.53 & 406.81 & 404.27 & 401.47 & 398.87 \\
3 & 1039.35 & 1038.80 & 1037.13 & 1032.59 & 1026.58 & 1020.04 & 1013.69 \\
4 & 1049.25 & 1048.31 & 1045.41 & 1039.22 & 1032.17 & 1024.31 & 1016.05 \\
5 & 1153.46 & 1152.70 & 1150.33 & 1144.81 & 1137.55 & 1129.28 & 1121.06 \\
6 & 1865.67 & 1863.95 & 1858.75 & 1847.87 & 1835.45 & 1821.42 & 1807.30 \\
7 & 1905.70 & 1904.31 & 1900.18 & 1889.76 & 1877.31 & 1864.01 & 1851.69 \\
8 & 2838.08 & 2835.21 & 2826.39 & 2804.30 & 2779.33 & 2753.70 & 2731.30 \\
9 & 3336.45 & 3328.47 & 3303.94 & 3268.14 & 3233.70 & 3190.08 & 3141.72 \\
10 & 3534.31 & 3526.24 & 3501.77 & 3462.89 & 3426.04 & 3381.89 & 3337.02 \\
11 & 3742.80 & 3734.81 & 3710.27 & 3673.89 & 3637.72 & 3591.62 & 3539.64 \\
12 & 4158.09 & 4154.89 & 4149.21 & 4143.50 & 4134.89 & 4124.96 & 4115.11 \\
\hline
\end{tabular}
\end{tabular}

tle effect on the vibration of the vibration table. In addition, no axial stretching or compressing modes of the vibrator exist within 10 times the maximum operating frequency of the vibrator $(300 \mathrm{~Hz})$. Further analysis shows that the mode shapes of the vibrator do not change with temperature.

Tab. 6 presents the first 12 orders of the natural frequency of the vibrator with different environmental test chamber temperatures. The results show that the natural frequency for each order decreases as the temperature increases. When the temperature increases from $22{ }^{\circ} \mathrm{C}$ to $300{ }^{\circ} \mathrm{C}$, the natural frequency for the first order decreases from $401.14 \mathrm{~Hz}$ to $389.21 \mathrm{~Hz}$, which is a relative deviation of approximately $2.97 \%$. Therefore, the effect of the temperature field on the natural frequency of a structure must be considered when designing a vibrator, especially for a wide temperature range.

\subsubsection{Influence of the temperature field on structural vibration}

To further analyze the factors that affect the vibration of an elastic structure, a modal analysis of the vibrator is carried out without considering thermal stress. Since no displacement constraints or force loads are incorporated in the structure in the free modal analysis, the elastic strain will be $\varepsilon=0$. Therefore, according to Eq. (18), the thermal expansion coefficient, $\beta$, of all the materials is set to 0 to make the thermal strain $\varepsilon_{0}=0$. In this case, thermal stress is omitted from the FEM analysis, according to Eq. (20), and the solution procedure is the same as that shown in Fig. 1. Tab. 7 shows the first two orders of the natural frequency of the vibrator and the results obtained when thermal stress is considered or neglected together with the temperature changes. The results show that the natural frequencies obtained when considering thermal stress are slightly higher than the natural frequencies obtained when thermal stress is not taken into account, and the relative deviation between the two cases increases with temperature. The reason for the increase in the relative deviation is that as the temperature increases, the local thermal stress grows, leading to an increase in the impact on the stiffness matrix. However, the relative deviation of the natural frequencies calculated for these two cases is very small. Even when the temperature increases to $300{ }^{\circ} \mathrm{C}$, the maximum relative deviation between the two cases is only $0.01 \%$. Therefore, the influence of structural thermal stress can be neglected in the modal analysis of the vibrator in this study, and only the change in the material properties with temperature needs to be considered, especially for a structure that experiences temperature variations. Moreover, the decrease in the natural frequency with temperature shown in Tab. 6 can be explained. The elastic modulus of the material
Table 7. Effect of thermal stress on the natural frequency of the vibrator.

\begin{tabular}{|c|c|c|c|c|c|c|}
\hline \multirow{2}{*}{$\begin{array}{l}T_{\text {in }} / \\
{ }^{\circ} \mathrm{C}\end{array}$} & \multicolumn{3}{|c|}{$1^{\text {st }}$ order natural frequency } & \multicolumn{3}{|c|}{$2^{\text {nd }}$ order natural frequency } \\
\hline & $\begin{array}{l}\text { Thermal } \\
\text { stress con- } \\
\text { sidered / } \\
\mathrm{Hz}\end{array}$ & $\begin{array}{l}\text { Thermal } \\
\text { stress } \\
\text { ignored / } \\
\text { Hz }\end{array}$ & $\begin{array}{l}\text { Relative } \\
\text { deviation / } \\
\%\end{array}$ & \begin{tabular}{|l|} 
Thermal \\
stress con- \\
sidered / \\
$\mathrm{Hz}$
\end{tabular} & \begin{tabular}{|l|} 
Thermal \\
stress \\
ignored / \\
Hz
\end{tabular} & $\begin{array}{l}\text { Relative } \\
\text { deviation / } \\
\%\end{array}$ \\
\hline 100 & 399.99 & 399.98 & 0.003 & 408.53 & 408.52 & 0.002 \\
\hline 150 & 398.01 & 397.99 & 0.005 & 406.81 & 406.79 & 0.005 \\
\hline 200 & 395.32 & 395.29 & 0.008 & 404.27 & 404.24 & 0.007 \\
\hline 250 & 392.24 & 392.21 & 0.008 & 401.47 & 401.44 & 0.007 \\
\hline 300 & 389.21 & 389.18 & 0.008 & 398.87 & 398.83 & 0.010 \\
\hline
\end{tabular}

decreases as the temperature increases, resulting in a reduction in the stiffness matrix of the structure and a decrease in the natural frequency.

\section{CONCLUSIONS}

The dynamic characteristics of an elastic structure with thermal effects are studied based on a combination environmental testing device. The following conclusions can be drawn.

The mechanism of the thermal effect on the dynamic characteristics of an elastic structure is presented, and the modal analysis process with thermal effects based on FEM is given. The modal analysis of a vibrator with thermal effects is carried out using ANSYS Workbench 16.0. The influence of the temperature field on dynamic characteristics, including variations in material properties due to temperature variations, and the additional initial stress element stiffness matrix caused by structural thermal stress. The simulation results show that the natural frequency of the vibrator for each order decreases as the temperature increases, while the mode shapes of the vibrator do not change with temperature. Furthermore, although thermal stress may affect the natural frequency due to additional initial stress element stiffness, this stress can be neglected in the modal analysis because it is negligible relative to the effect of material property changes with temperature.

These results will be helpful for improving the structural dynamics of a vibration table in a combination environmental test, especially when the vibrator is strongly affected by a temperature field. Moreover, this method can be applied to other structural designs when structural dynamics are coupled with a thermal environment.

\section{ACKNOWLEDGEMENTS}

This research was supported by the National Natural Science Foundation of China (Grant No. 51805477), the Natural Science Foundation of Jiangsu Province for Young Scholars (Grant No. BK20150397), the Postdoctoral Science Foundation of China (Grant No. 2018M632453), and the Shanghai Sailing Program (Grant No. 18YF1409800).

\section{REFERENCES}

1 Yang, J., Shen, H. S., Vibration characteristic and transient response of shear-deformable functionally graded plates in thermal environment, Journal of Sound and Vibration, 255(3), 579-602, (2002). https://dx.doi.org/10.1006/jsvi.2001.4161

2 Jeyaraj, P., Ganesan, N., Padmanabhan, C., Vibration and acoustic response of a composite plate with inher- 
ent material damping in a thermal environment, Journal of Sound and Vibration, 320(1-2), 322-338, (2009). https://dx.doi.org/10.1016/j.jsv.2008.08.013

3 Kumar, B. R., Ganesan, N., Sethuraman, R., VibroAcoustic Analysis of Functionally Graded Elliptic Disc under Thermal Environment, Mechanics of Advanced Materials and Structures, 16, 160-172, (2009). https://dx.doi.org/10.1080/15376490802625506

${ }^{4}$ Li, Q., Lu, V. P., Kou, K. P., Three-dimensional vibration analysis of functionally graded material sandwich plates, Journal of Sound and Vibration, 311(1), 498-515, (2009). https://dx.doi.org/10.1016/j.jsv.2007.09.018

5 Duc, N. D., Tung, H. V., Nonlinear response of pressure-loaded functionally graded cylindrical panels with temperature effects, Composite Structures, 92(7), 1664-1672, (2010). https://dx.doi.org/10.1016/j.compstruct.2009.11.033

6 Malekzadeh, P., Beni, A. A., Free vibration of functionally graded arbitrary straight-sided quadrilateral plates in thermal environment, Composite Structures, 92(11), 2758-2767, (2010). https://dx.doi.org/10.1016/j.compstruct.2010.04.011

7 Malekzadeh, P., Shahpari, S. A., Ziaee, H. R., Three-dimensional free vibration of thick functionally graded annular plates in thermal environment, Journal of Sound and Vibration, 329(4), 425-442, (2010). https://dx.doi.org/10.1016/j.jsv.2009.09.025

8 Liu, Y, Li, Y, Vibration and acoustic response of rectangular sandwich plate under thermal environment, Shock and Vibration, 20(5), 1011-1030, (2013). https://dx.doi.org/10.1155/2013/281723

9 Li, W., Li, Y., Vibration and sound radiation of an asymmetric laminated plate in thermal environments, Acta Mechanica Solida Sinica, 28(1), 11-22, (2015). https://dx.doi.org/10.1016/s0894-9166(15)60011-8

$10 \mathrm{Li}, \mathrm{X}$., Yu, K., Vibration and acoustic responses of composite and sandwich panels under thermal environment, Composite Structures, 131, 1040-1049, (2015). https://dx.doi.org/10.1016/j.compstruct.2015.06.037

11 Pandey, S., Pradyumna, S., Free vibration of functionally graded sandwich plates in thermal environment using a layerwise theory, European Journal of Mechanics - A/Solids, 51, 55-66, (2015). https://dx.doi.org/10.1016/j.euromechsol.2014.12.001

12 Padhi, A., Pandit, M. K., Behaviour of sandwich laminates subjected to thermal loading using higher-order zig-zag theory, Journal of Sandwich Structures and Materials, 18(2), 174-199, (2016). https://dx.doi.org/10.1177/1099636215613487

13 Huang, S. Y., Wang, Z. Y., The structure modal analysis with thermal environment, Missile Space Vehicle, 303(5), 50-56, (2009). https://dx.doi.org/10.3969/j.issn.10047182.2009.05.012
14 Wang, H. H., Chen, H. H., Cui, X. L., et al., Thermal effect on dynamic characteristics of a missile wing, Journal of $\mathrm{Vi}$ bration Measurement \& Diagnosis, 30(3), 275-279, (2010). https://dx.doi.org/10.3724/SP.J.1077.2010.01195

15 Wu, Z. Q., Cheng, H., Zhang, W., et al., Effect of thermal environment on dynamic properties of aerospace vehicle panel structures, Acta Aeronautica et Astronautica Sinica, 34(2): 334-342, (2013). https://dx.doi.org/10.7527/S10006893.2013.0038

$16 \mathrm{He}$, X. D., Wu, S., Zhang, B. Y., et al., Influence of thermal stress on vibration frequencies of a wing structure, Journal of Vibration Measurement \& Diagnosis, 35(6), 11341139, (2015). https://dx.doi.org/10.16450/j.cnki.issn.10046801.2015.06.021

17 Tan, G. H., Li, Q. Y., Deng, J., Test and analysis of natural modal characteristics of a wing model with thermal effect, Acta Aeronautica et Astronautica Sinica, 37(s1), 32-37, (2016). https://dx.doi.org/10.7527/S1000-6893.2016.0148

18 Li, Y. F., He, L. L., Zhang, X., et al., Thermal modal analysis of typical thermos-defend panel structure, Chinese Journal of Applied Mechanics, 34(1), 43-49, (2017). https://dx.doi.org/10.11776/cjam.34.01.C044

19 Avsec, J., Oblak, M., Thermal vibrational analysis for simply supported beam and clamped beam, Journal of Sound and Vibration, 308(3), 514-525, (2007). https://dx.doi.org/10.1016/j.jsv.2007.04.002

20 Geng, Q., Li, Y., Solutions of dynamic and acoustic responses of a clamped rectangular plate in thermal environments, Journal of Vibration and Control, 22, 1593-1603, (2014). https://dx.doi.org/10.1177/1077546314543730

21 Zou, B., H,u Y., Liu, Z., et al., The Impact of Temperature Effect on Exhaust Manifold Thermal Modal Analysis, Research Journal of Applied Sciences Engineering \& Technology, 6(15), 2824-2829, (2013). https://dx.doi.org/10.19026/rjaset.6.3792

22 Sabour, M. H., Bhat, R. B., Vibration of rotating structures in thermal environment, Advances in Vibration Engineering, 7(2), 167-180, (2008).

23 Ai, S. M., Wang, K. M., Miao H., et al., Thermal-structural coupling analysis of turbine stator of a type of aeroengine, Journal of Shenyang Aerospace University, 29(1), 26-30, (2012). https://dx.doi.org/10.3969/j.issn.20951248.2012.01.006

${ }^{24}$ Li, Z. N., Yuan, H. Q., Song L., Analysis of influence on natural characteristics of gear by thermal effect, Journal of Machine Design, 29(12), 22-25, (2012). https://dx.doi.org/10.13841/j.cnki.jxsj.2012.12.021

$25 \mathrm{Gu}, \mathrm{L}$., Qin, Z., Chu, F., Analytical analysis of the thermal effect on vibrations of a damped Timoshenko beam, $\mathrm{Me}$ chanical Systems \& Signal Processing, 60-61(52), 619-643, (2015). https://dx.doi.org/10.1016/j.ymssp.2014.11.014

26 Wang, X. C., Finite element method, Tsinghua university press, Beijing, (2003).

27 Nithiarasu, P., Lewis, R.W., Seetharamu, K.N., Fundamentals of the finite element method for heat and mass transfer, Wiley, Chichester, (2016). 